\title{
OLHAR DISCENTE DO CURSO DE ENFERMAGEM SOBRE O ENSINO HÍBRIDO - OFICINAS VIRTUAIS
}

\author{
LORENA/SP MAIO/2018 \\ Maria Cristina Marcelino Bento - UNESP e UNIFATEA - criscabento@gmail.com \\ Neide Aparecida Arruda de Oliveira - UNIFATEA - mnoliveira9@gmail.com \\ Luciani Vieira Gomes Alvarei - UNIFATEA e FATEC de Cruzeiro - luciani.alvareli@gmail.com
}

Tipo: Investigação Científica (IC)

Natureza: Descrição de Projeto em Andamento

Categoria: Pesquisa e Avaliação

Setor Educacional: EDUCAÇÃO SUPERIOR

\begin{abstract}
RESUMO
O trabalho apresentado é uma fração do projeto de pesquisa intitulado Propósito do uso do Ambiente Virtual de Aprendizagem (AVA) em Instituição de Ensino Superior Salesiana. Esta pesquisa tem como objetivo verificar o olhar discente do curso de Enfermagem mediante a utilização do ensino híbrido por meio de Oficinas elaboradas pelos docentes do curso e oferecidas aos discentes de Enfermagem. A organização e desenvolvimento da pesquisa-ação apontam para a ampliação do uso desta metodologia de ensino, bem como a melhoria do uso dos recursos educacionais digitais, pois os sujeitos consideraram que a modalidade de ensino apresentada amplia as experiências de aprendizagem que podem influir diretamente na formação profissional. Sugere-se a valorização, inovação e formação para o trabalho docente no ensino superior para esta modalidade.
\end{abstract}

Palavras-chave: Enfermagem. Ensino Híbrido. Ensino Superior. 


\section{Introdução}

A formação do enfermeiro, no Brasil, está descrita na Diretriz Curricular Nacional de 03/2001, regulamentada pelo Parecer de № 1133/2001, propondo a formação deste profissional em cursos de graduação. Tem-se, a partir do exposto, que os docentes deste curso são profissionais da área que lecionam, e como apresentado por Masseto (2012), não são profissionais formados para a docência.

A ação docente neste início do século XXI - era das tecnologias digitais móveis e sem fio, ou ainda chamada de sociedade 3.0, precisa ser pautada na formação discente deste tempo, uma vez que o egresso do ensino superior, neste caso, o aluno enfermeiro, é usuário dessas tecnologias e dela necessita em todos os momentos e lugares.

As tecnologias digitais, cada vez mais, têm se transformado em recursos pedagógicos para auxiliar o processo de ensino e aprendizagem, o que exige do docente saber escolher e adaptá-las ao universo acadêmico para utilizá-las favorecendo a aprendizagem dos alunos.

Desta forma, e urgente a revisão e reinvenção dos processos metodológicos até então adotados, superando o uso do quadro negro e giz, de modo que o planejar, implementar e avaliar a aula estejam focados no aluno e em seu contexto, repleto de novas tecnologias.

Uma possibilidade muito enriquecedora está na necessária reflexão sobre o uso das tecnologias digitais, combinando aulas presenciais e online, mantendo-se o melhor da sala de aula tradicional e inserindo inovações trazidas pela adoção de novas tecnologias, ou seja, pela adoção do ensino híbrido.

A pesquisa apresentada tem como objetivo: verificar o olhar discente mediante a utilização do ensino híbrido por meio de Oficinas elaboradas pelos docentes do curso de Enfermagem de uma instituição particular de ensino superior localizada no interior do estado de São Paulo.

\section{Referencial Teórico}

Valente (2014) considera o ensino híbrido de acordo com os quatro modelos que categorizam a maioria dos programas de ensino híbrido: Flex, Blended Misturado, Virtual Enriquecido e rodízio. (Quadro 1) 
Quadro 1- Quatro Modelos do Ensino Híbrido

\begin{tabular}{|c|c|c|c|}
\hline Flex & Blended misturado & Virtual enriquecido & Rodizio \\
\hline 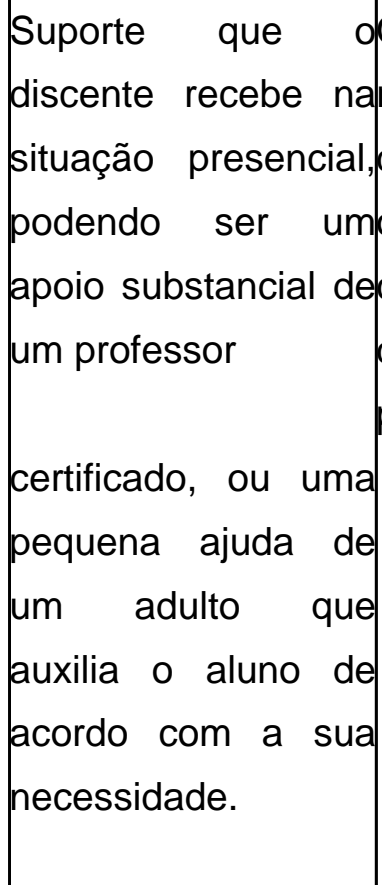 & $\begin{array}{l}\text { aluno opta po } \\
\text { realizar uma ou mais } \\
\text { disciplinas totalmente } \\
\text { on-line para } \\
\text { complementar as } \\
\text { disciplinas } \\
\text { presenciais. }\end{array}$ & 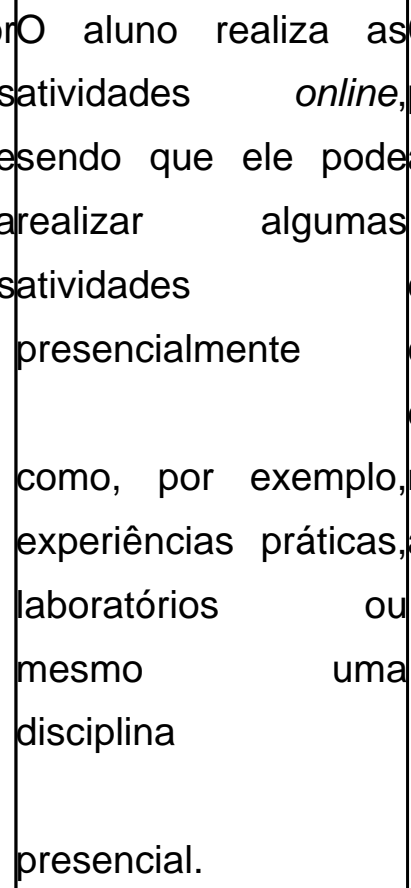 & $\begin{array}{l}\text { Consiste } \\
\text { proporcionar } \\
\text { aluno a chance } \\
\text { de alternar ou } \\
\text { circular } \\
\text { diferentes } \\
\text { modalidades de } \\
\text { aprendizagem. }\end{array}$ \\
\hline
\end{tabular}

Fonte: autoras a partir de Valente (2014)

Consideram-se as formas de rodízio, mencionadas no Quadro 1 por meio de quatro formas: rotação por estações, laboratório rotacional, rotação individual e sala de aula invertida.

$\mathrm{Na}$ rotação por estações: os estudantes podem realizar diferentes atividades, em diferentes estações, no espaço da sala de aula. No laboratório rotacional: os estudantes usam o espaço da sala de aula e laboratórios. Já na rotação individual: cada aluno tem uma lista de propostas que deve contemplar em sua rotina para cumprir os temas a serem estudados. E por fim, a sala de aula invertida: quando a teoria é estudada em casa, no formato online ou não, e o espaço da sala de aula é utilizado para discussões, resolução de atividades, entre outras propostas de atividades.

O docente que utiliza esta metodologia precisa cuidar para que consiga "desafiar" o aluno em todos os momentos do processo de ensino e aprendizagem. O rodízio individual exige do professor tempo para organizar um conjunto de atividades por discente, mediante necessidades e ritmos de aprendizagem de cada discente. 
Do mesmo modo, o docente precisa refletir em como provocar a curiosidade do aluno como fonte de motivação para os estudos por meio de técnicas como debate, por exemplo, ou no espaço online ou mesmo no presencial. Outro item fundamental para que essa metodologia alcance os resultados almejados está relacionado ao papel desempenhado pelo docente, que precisa assumir a postura de professor mediador, orientando, conduzindo, facilitando o processo de ensino e aprendizagem por meio do formato das atividades e de seu discurso com os alunos.

Esta metodologia de aula exige mais tempo do docente, preparo do material de estudo adequado por turma e aluno, o que reflete a ajuda de pessoal especializado, pois nem sempre o docente consegue realizar estas tarefas sozinho, seja pelo tempo ou pelos conhecimentos tecnológicos.

O aluno, ao compreender a importância desta metodologia, poderá desenvolver a autonomia ou domínio no aprender, aprendendo a estudar, a refletir criticamente e não apenas a decorar conteúdos para obter nota em provas.

\section{Procedimentos Metodológicos}

De modo a atender aos objetivos desta pesquisa adotou-se a pesquisa-ação que, segundo Tripp (2005), auxilia no aprimoramento da prática docente pela oscilação sistemática entre agir no campo da prática e investigar a respeito dela. Planeja-se, implementa-se, descreve-se e avalia-se uma mudança para a melhora de sua prática, aprendendo mais, no decorrer do processo, tanto a respeito da prática quanto da própria investigação.

Desta forma, organizou-se a pesquisa-ação da seguinte forma: planejar - a oficina Saúde do Idoso foi elaborada pelo professor da disciplina, e a oficina da disciplina Centro Cirúrgico foi confeccionada em parceria com equipe do Núcleo de Educação a Distância (NEAD) da IES por meio dos aplicativos do site H5P.

O site H5P.org é um site de código aberto que facilita a criação de conteúdo interativo, fornecendo uma variedade de tipos de conteúdo para várias necessidades; agir montagem das oficinas; observar - ocorreu mediante a realização das oficinas e análise das respostas do questionário; implementação: disponibilização da oficina aos alunos no AVA da IES; reflexão - a análise dos dados coletados por meio do questionário, que proporcionou a reflexão pelos organizadores da pesquisa, coordenador do curso, os docentes das disciplinas citadas, equipe NEAD e pelo núcleo docente estruturante do curso para o planejamento e organização de oficinas futuras. 
A instituição pesquisada adota o uso de ambiente virtual de aprendizagem - AVA, pelo viés da educação online. Consta no Plano de Desenvolvimento Institucional (PDI) da instituição as formas de uso mediante a legislação do ensino superior brasileiro, bem como estão descritas no Projeto Político Pedagógico do Curso - PPC. O local de pesquisa referenciado possui equipe que oferece formação docente; destacamos para esta pesquisa, a oferta ao incentivo de uso de metodologias ativas - ensino híbrido e uso de aplicativos em educação escolar. As atividades online acontecem por meio de oficinas virtuais que são consideradas extensão das aulas presenciais.

Analisou-se as oficinas ofertadas aos alunos e atividades realizadas em duas disciplinas do curso de Enfermagem - Centro Cirúrgico e Saúde do Idoso.

Estas disciplinas são ministradas em 3 momentos diferentes: aulas presenciais em sala de aula, espaços diferenciados e online, perfazendo o ensino híbrido como exposto anteriormente.

A pesquisa foi realizada com quinze graduandos, do $3^{\circ}$ ano do curso de Enfermagem de uma Instituição de Ensino Superior Salesiana, localizada na região do Vale do Paraíba do Sul, interior do Estado de São Paulo. Desses, doze sujeitos do sexo feminino e três do sexo masculino. Siqueira et. al. (2017, p.53) afirma que "a enfermagem consolidou a sua prática como uma ocupação essencialmente de mulheres, entretanto o número de profissionais de enfermagem do sexo masculino cresce a cada ano.".

Os discentes aceitaram, livremente, participar, após tomarem ciência do projeto de pesquisa, que foi aprovado pelo Comitê de Ética em Pesquisa do UNIFATEA, sob Parecer Consubstanciado de no. CAAE: 85648018.7.0000.543.

\section{Apresentação e Discussão dos Resultados}

Os dados foram coletados por meio de um questionário como proposto por Vieira (2009), dividido em três partes, a saber: primeira designada a verificar o perfil do sujeito; a segunda parte objetivava conhecer a opinião dos sujeitos sobre as oficinas virtuais de todo o curso; e a última parte composta por cinco questões abertas para verificar a aprendizagem dos sujeitos.

\subsection{Perfil dos sujeitos}

A questão inicial do questionário tinha como objetivo verificar a idade dos sujeitos, para a análise da metodologia proposta e uso dos recursos digitais; seis sujeitos possuem idade superior a 29 anos, outros seis têm entre 25 e 28 anos, e três possuem de 19 a 24 anos. 
Solicitou-se aos sujeitos que assinalassem a cidade em que residem, pois interessa verificar como o ensino híbrido, neste caso, pode facilitar ou não os estudos dos sujeitos que moram em cidades diferentes da que estudam. Três sujeitos residem na cidade em que estudam, seis em Guaratinguetá, e os demais residem em diferentes localidades, a saber: Canas, Aparecida, Cunha, Cruzeiro, Potim e Piquete. Mediante a diversidade de localização dos sujeitos, infere-se que o estudo online se constitui em uma forma de alargamento da sala de aula favorecendo e/ou facilitando o encontro aluno/aluno e alunos/docente.

A última questão relacionada ao perfil do sujeito tinha como objetivo verificar se os sujeitos possuíam bolsa de estudo, cinco assinalaram não, sete possuíam bolsa PROUNI e três FIES.

Considerando o perfil do egresso do curso de enfermagem, tem-se que a turma é heterogênea. De acordo com a faixa etária, nem todos os sujeitos podem ser considerados nativos digitais, mas infere-se que devem saber da importância do uso diversificado de recursos e modalidades de aula para a aprendizagem.

\subsection{Oficinas do curso}

A primeira questão da segunda parte do questionário referiu-se a qual meio tecnológico o discente realizou as oficinas no AVA. Esta questão é importante para a equipe NEAD devido à programação do formato do AVA. Os meios apresentados foram: notebook, celular, computador da instituição de ensino e tablet, sendo o notebook e o computador da instituição de ensino os mais assinalados.

Indagou-se aos sujeitos se eles realizaram todas as oficinas, apenas algumas, algumas institucionais ou todas as oficinas institucionais; somente um sujeito não realizou todas as oficinas.

A terceira questão referia-se a como os discentes classificavam as oficinas em geral. Sobre o conteúdo e a apresentação, o questionário continha duas questões separadas, uma para cada item, os resultados ficaram iguais, assim: ótimo com dois, boa com onze, e três para regular.

A próxima questão estava relacionada à quantidade, ao tamanho do conteúdo das oficinas. Quanto ao volume, os discentes poderiam assinalar como: grande, adequado e pequeno. Um sujeito registrou adequado, quatorze registraram adequado.

Solicitou-se aos discentes considerações sobre o conteúdo das oficinas como algo novo, 
se era complementar aos conteúdos dados em sala de aula, se era repetitivo simplesmente ou se era repetitivo, porém necessário para reforçar os conteúdos estudados em sala de aula. Nove sujeitos consideraram o conteúdo complementar e três presumiram repetitivo e outros três repetitivo, porém necessário.

Cada oficina continha conteúdo e questionário com correção automática pelo AVA. Perguntou-se aos sujeitos se o questionário era muito extenso, extenso e adequado, adequado ou pequeno. O questionário foi considerado adequado por sete sujeitos, extenso e adequado foi assinalado por cinco, três marcaram muito extenso.

Mediante as respostas dos sujeitos, as oficinas são consideradas boas. Destaca-se que os docentes do curso pesquisado foram incentivados pelo coordenador a participarem da formação tecnológica docente ofertada pelo NEAD da IES, momento em que a equipe auxiliou um grupo de professores na elaboração do material utilizando o Sway e o Abode Sparks.

Estes aplicativos oferecem cotas gratuitas para uso. Sway é um aplicativo (app) digital da empresa Microsoft, apresentado como um app contador de histórias, que pode ser usado no trabalho, na escola e em casa. Adobe Spark é um produto da Adobe, desenvolvido para ser mais acessível aos usuários que não desenvolveram muitas habilidades de design e/ou não dominam as ferramentas mais avançadas de aplicativos para apresentação e/ou criação de imagens.

\subsection{Oficinas das disciplinas: saúde do idoso e centro cirúrgico}

As questões nesta parte do questionário eram do tipo abertas. Requisitou-se aos sujeitos que descrevessem a organização do material das oficinas das disciplinas Saúde do Idoso e Centro Cirúrgico. Doze sujeitos descreveram que as oficinas eram ótimas, entretanto o formato da oficina do Centro Cirúrgico era melhor, mais objetivo. A oficina mencionada pelos sujeitos foi composta por: jogo da memória, agamoto, flashcards, dialog cards e acordion, podendo o leitor consultar em: https://h5p.org/content-types-andapplications. Três sujeitos descreveram que os estudos no AVA atrapalham, pois não possuem tempo para isso.

A próxima interrogação foi realizada para verificar como as oficinas auxiliaram na aprendizagem dos sujeitos. Doze sujeitos registraram que as oficinas ajudaram muito na aprendizagem, pois na oficina Saúde do Idoso, "as questões foram retiradas de concursos e isso ajuda muito" (a última frase foi dita por 3 sujeitos). A Oficina em Centro Cirúrgico ajudou muito, também, pois "(...) pudemos estudar/ler e reler o conteúdo, assim ficou mais fácil, mas faltou visitar o centro cirúrgico." Esta resposta está 
relacionada ao fato desta oficina ter o conteúdo organizado pelo H5P, equilíbrio entre apresentação do conteúdo e exercícios próximos, com feedback imediato. Três sujeitos não responderam.

A pergunta seguinte foi introduzida com a intenção de verificar como os dois momentos diferentes da aula auxiliam na aprendizagem dos alunos. Quatro sujeitos registraram que toda forma de aprendizagem é bem-vinda, cinco sujeitos descreveram quando se tem preocupação com a aprendizagem do aluno a aula se modifica, três mencionaram que facilita as atividades práticas, destacando a segurança no que se aprende, destes três um afirmou que: a aula fica mais interessante quando nos propõe diversidade para aprender e três não responderam.

A penúltima pergunta, foi realizada para verificar em que medida o formato da aula facilita a aprendizagem: imagem e informação juntas facilita a compreensão do conteúdo; nada de textos longos; formas diferentes para um mesmo conteúdo, colabora na compreensão e memorização quando é o caso, três sujeitos não responderam. Sobre a oficina Saúde do Idoso, os sujeitos responderam que: havia muito texto, mas o conteúdo era necessário. Dez sujeitos solicitaram que é preciso rever o formato da oficina, se possível torná-la semelhante à do centro cirúrgico. Um sujeito destacou que "(...) quando as aulas motivam para a aprendizagem, se esquece ou deliga-se de notas, assim o profissional é melhor preparado.".

A última indagação tinha como objetivo verificar se os sujeitos concordavam que todas as disciplinas do curso deveriam ser adaptadas para o modelo híbrido - aulas presencias com o alargamento da sala de aula e online. Dez sujeitos entenderam que as aulas já acontecem desta forma presencial e online por meio das oficinas. Destes dez sujeitos, sete entenderam que não adiantava copiar o formato de outra aula, é melhor entender o que os alunos precisam aprender para preparar a aula online. Dois sujeitos descreveram que todas as aulas do curso deveriam ser trabalhadas de modo híbrido, ou como tido por eles, sempre em ambientes fora da faculdade, também. Três sujeitos não responderam.

\section{Conclusão}

É salutar que as Instituições de Ensino Superior tenham presença online, mesmo que seja apenas como apoio ao ensino presencial inicialmente. Nesse sentido, as universidades estão alavancando tendências de aprendizagem híbrida (Blended Learning), combinando os métodos de ensino e aprendizagem presencial e online.

A adoção de novas propostas metodológicas proporciona ambientes de aprendizagens 
mais flexíveis, ativas e atraentes para os estudantes, tornando-os mais motivados e interessados em aprender. Para isso, vários fatores são necessários, tais como: conhecer o perfil do aluno e a forma como ele aprende, adequação do perfil do professor, utilização de ferramentas digitais e analógicas interativas que auxiliem na motivação do estudante, tornando-o protagonista do processo de ensino e aprendizagem.

O desafio é imenso, mas por meio da coleta de dados, análise e reflexão sobre a prática pedagógica, deve-se aperfeiçoar o atual cenário, vivenciando um processo de melhoria contínua.

Pelo olhar dos sujeitos, nesta fração da pesquisa, o ensino hibrido foi uma escolha acertada para o curso de Enfermagem e ele deve processar-se para além do espaço virtual, determinando a ampliação das parcerias entre instituições de ensino superior com outros espaços espaços da sociedade; cuidando do formato do material/aulas/oficinas no ambiente virtual.

\section{Referências}

BRASIL. Diretrizes Curriculares. Cursos de Graduação Enfermagem. Ministério da Educação. MEC. Disponível em:< http://portal.mec.gov.br/cne/arquivos/pdf/CES03.pdf> Acesso em: 01 abr. 2018.

MASSETO, M. T. Competência Pedagógica do Professor Universitário. 2 ed. São Paulo: Summus, 2012.

SIQUEIRA, A.O. de S. Enfermeiros homens: igualdade de gênero. Revista Saúde - UNGSER. V.1, n.11, 2017, p.53.

TRIPP, D. Pesquisa-ação: uma introdução metodológica. Tradução de: Oliveira, Lólio. Educação e Pesquisa, São Paulo, v.31, n. 3, set/dez.2005, p. 443-466,

VALENTE, J. A. Blended learning e as mudanças no ensino superior: a proposta da sala. Educar em Revista, Curitiba, Brasil, Editora UFPR. Edição Especial n. 4/2014, p. 79-97.

VIEIRA, Sonia. Como elaborar questionários. São Paulo: Atlas, 2009. 